\title{
A systematic review and meta-analysis of independent risk factors for postherpetic neuralgia
}

\author{
Haiou Zhou ${ }^{1}$, Zhiguang Wang ${ }^{1}$, Haifei Jin ${ }^{1}$, Xing Chen $^{2}$, Long Lei ${ }^{1}$ \\ ${ }^{1}$ Department of Anesthesiology, Zhejiang Rongjun Hospital, The Third Affiliated Hospital of Jiaxing University School of Medicine, Jiaxing, China; \\ ${ }^{2}$ Department of Dermatology, Zhejiang Rongjun Hospital, The Third Affiliated Hospital of Jiaxing University School of Medicine, Jiaxing, China \\ Contributions: (I) Conception and design: H Zhou, X Chen, L Lei; (II) Administrative support: Z Wang; (III) Provision of study materials or patients: \\ H Zhou; (IV) Collection and assembly of data: H Zhou, X Chen, L Lei; (V) Data analysis and interpretation: H Zhou; (VI) Manuscript writing: All \\ authors; (VII) Final approval of manuscript: All authors. \\ Correspondence to: Xing Chen. Department of Dermatology, Zhejiang Rongjun Hospital, The Third Affiliated Hospital of Jiaxing University School \\ of Medicine, 309 Shuangyuan Road, Nanhu District, Jiaxing 314000, China. Email: chenxing08302021@163.com; Long Lei. Department of \\ Anesthesiology, Zhejiang Rongjun Hospital, The Third Affiliated Hospital of Jiaxing University School of Medicine, 309 Shuangyuan Road, Nanhu \\ District, Jiaxing 314000, China. Email: Leilong4650@sina.com.
}

\begin{abstract}
Background: This study aimed to explore the independent risk factors for postherpetic neuralgia (PHN). Methods: Related studies of PHN risk factors were searched in PubMed for screening and meta-analysis. In this study, data from studies included were extracted and summarized, including odds ratio (OR) value, 95\% confidence interval (CI), P value, sample size, and the number of patients with and without PHN. The chi-square test was used for heterogeneity test. Sensitivity analysis was conducted by excluding low-quality studies and using different model analysis.
\end{abstract}

Results: A total of 14 studies were further screened for meta-analysis, including 4,192 patients with herpes zoster. Of these patients, $478(11.40 \%)$ had neuralgia and 3,714 (88.60\%) did not have neuralgia. Age [OR $=1.59 ; 95 \% \mathrm{CI}:(1.23,2.04) ; \mathrm{Z}=3.62 ; \mathrm{P}<0.001]$, acute severe pain in the herpes stage $[\mathrm{OR}=1.49 ; 95 \% \mathrm{CI}$ : (1.08, 2.08); $\mathrm{Z}=2.39 ; \mathrm{P}=0.02$ ], prodromal symptoms [OR =2.00; $95 \% \mathrm{CI}$ : $(1.16,3.44) ; \mathrm{Z}=2.48 ; \mathrm{P}=0.01$ ], and severe rash $[\mathrm{OR}=2.40 ; 95 \% \mathrm{CI}:(1.83,3.14) ; \mathrm{Z}=6.38 ; \mathrm{P}<0.001]$ were independent risk factors for $\mathrm{PHN}$. The funnel chart shows that there is no publication bias or geographic bias in the above independent risk factors. Gender $(\mathrm{Z}=0.37 ; \mathrm{P}=0.71)$ was not associated with $\mathrm{PHN}$, and the funnel chart shows that there is no publication bias or geographic bias.

Discussion: Age, acute pain, prodromal symptoms, and severe rash were independent risk factors for PHN.

Keywords: Postherpetic neuralgia (PHN); risk factors; meta-analysis

Submitted Sep 22, 2021. Accepted for publication Nov 17, 2021.

doi: 10.21037/apm-21-3028

View this article at: https://dx.doi.org/10.21037/apm-21-3028

\section{Introduction}

Postherpetic neuralgia (PHN) is a common sequela of herpes zoster $(1,2)$. PHN lacks a unified definition, mainly referring to the recurrence of pain symptoms after the local rash subsides or skin lesions heal. However, it should be emphasized that this pain symptom is different from acute pain (3). PHN persists after the herpes symptoms disappear and lasts a long time. Some patients may have pain for more than 1 year, and their pain is distributed along the innervated area. The incidence rate of herpes zoster is reported to be about $30 \%$, while the incidence rate of $\mathrm{PHN}$ is about $12.5 \%$ (4) of herpes zoster. At present, the pathogenesis of $\mathrm{PHN}$ is not clear, though it is widely considered to be the result of the combined action of peripheral nerve injury and signal changes of the central nervous system. Therefore, the main treatment measures need to not only block the excitation transmission of the peripheral nerve but also 
reduce the sensitivity of the central nerve. Nevertheless, some studies have pointed out that more than half of patients still cannot relieve pain under the condition of standardized treatment. PHN significantly reduces the quality of life of patients $(5,6)$. The risk factors for PHN are complex and diverse. It is widely believed that age, area at the time of herpes attack, insufficient antiviral therapy in the early stage, and severe organic disease are the independent risk factors. Studies have pointed out that severe immunosuppression and diabetes can increase the risk of PHN. Symptoms of systemic lupus erythematosus, recent trauma, and personality disorder may be related to PHN. Screening for independent risk factors of PHN and early clinical intervention are of great clinical significance for reducing the incidence rate of PHN. The purpose of this study was to search the literature on the risk factors of PHN and conduct a meta-analysis to provide a clinical decision-making basis for the prevention of PHN. We present the following article in accordance with the PRISMA reporting checklist (available at https://dx.doi. org/10.21037/apm-21-3028).

\section{Methods}

\section{Literature retrieval}

Based on the characteristics of PubMed's strong timeliness, high inspection rate, and only for documents in multiple languages, the relevant research literature on PHN was retrieved through PubMed. The search terms were ("postherpetic neuralgia" or "herpetic neuralgia" or "postherpetic pain") and ("risk factors" or "related factors").

\section{Literature screening}

The inclusion criteria were as follows: (I) the purpose of the research was to explore, analyze, or screen the independent risk factors of PHN; (II) the research method was to select independent risk factors by logistic regression analysis, taking PHN as the dependent variable and clinical factors as independent variables, including age, sex, pain degree, precursor symptoms, and rash, among others; (III) the odds ratio $(\mathrm{OR})$ value and $95 \%$ confidence interval $(\mathrm{CI})$ were calculated, or the OR value could be calculated; (IV) the literature has been published.

The literature exclusion criteria were as follows: (I) data had significant errors, errors, or low reliability; (II) improper use of literature research statistics; (III) documents were repeatedly published or only used for academic meetings and exchanges; (IV) the main content of the literature deviated from the research direction of this paper; $(\mathrm{V})$ the literature did not contain the relevant elements of this study. A total of 14 studies were included in this meta-analysis (1,5,7-18).

\section{Document data sorting}

In this paper, a researcher independently extracted and sorted the data in the literature, including the OR value of relevant variables, $95 \% \mathrm{CI}, \mathrm{P}$ value, sample size, and the number of patients with and without PHN. Two other researchers checked the extracted data.

\section{Literature quality evaluation}

In this paper, three researchers evaluated the quality of the included literature. The Newcastle-Ottawa scale (NOS) was used as the evaluation standard, where 0 to 3 points were judged as low quality, 4 to 6 points were regarded as medium quality, and 7 to 9 points were considered high quality. The quality evaluation was carried out independently by researchers. In case of inconsistency in the results of literature quality, the researchers would discuss and reach an agreement.

\section{Heterogeneity test and sensitivity analysis}

\section{Heterogeneity test}

Chi-square test is used for heterogeneity test. When the corrected $\mathrm{I}^{2}>50 \%$ of the degree of freedom, it is judged that there is heterogeneity between different studies. When the corrected $\mathrm{I}^{2} \leq 50$, it is judged that there is no heterogeneity analysis between different studies. For heterogeneity, the random effects model is used for meta-analysis. When there is heterogeneity between the studies, the random effects model is used; when there is no heterogeneity between the studies, the fixed effects model is used.

\section{Sensitivity analysis}

This study uses methods such as excluding low-quality studies and using different model analysis to conduct sensitivity analysis. After excluding relevant documents, the heterogeneity test was repeated, and the combined analysis model was selected. If there is no significant change in the results after the exclusion, the sensitivity is low and the results are credible. If the results change significantly after the exclusion, it indicates that the sensitivity is high and the robustness of the results is low, indicating that there are important and potential 


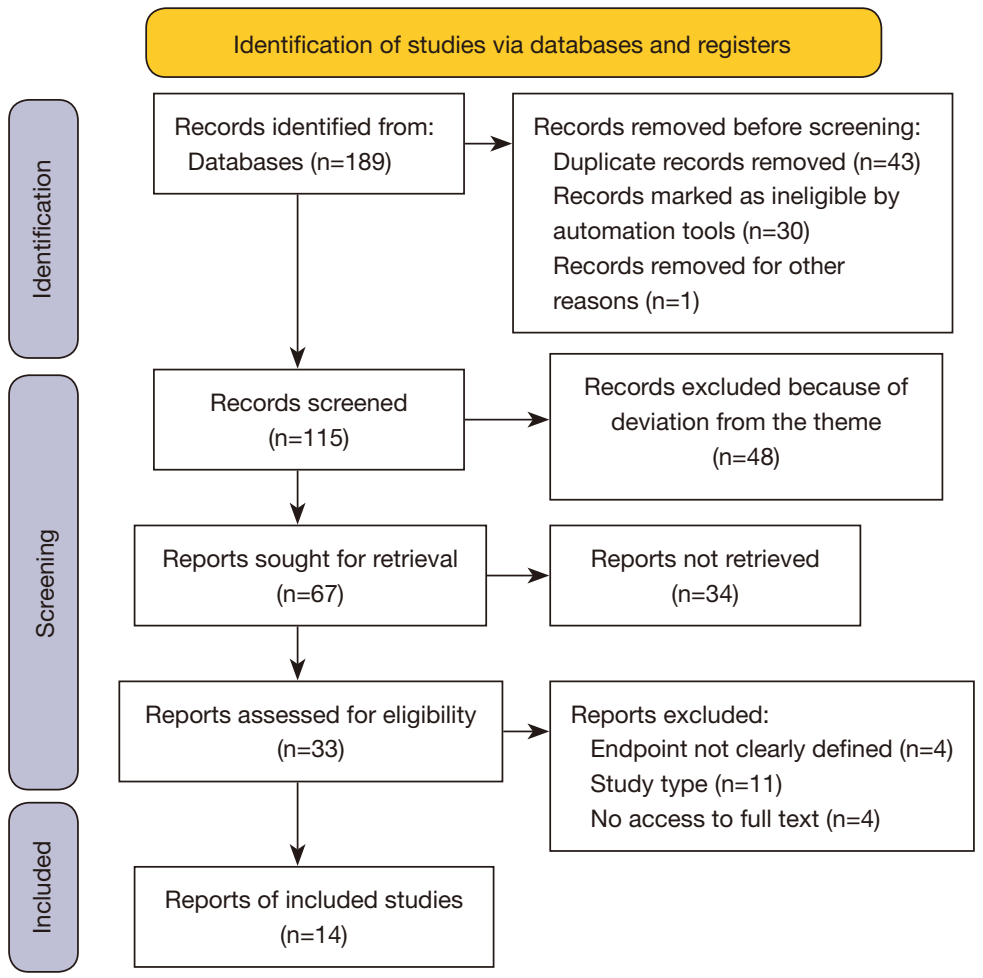

Figure 1 Literature search and selection are included in the meta-analysis flow chart.

bias factors related to the effect of intervention measures, and further clarifying the source of disputes.

\section{Statistical analysis}

The data were statistically analyzed by Cochrane software RevMan5.3. The OR value of variables and $95 \% \mathrm{CI}$ were used to statistically describe the effect size. $\mathrm{P}<0.05$ was statistically significant. In this study, the chi-square test was used to test the heterogeneity of the included literature. When the $\mathrm{I}^{2}$ corrected by degrees of freedom was more than $50 \%$, it indicated heterogeneity between the literature, and the random effects model was used. If the $\mathrm{I}^{2}$ corrected by degrees of freedom was $\leq 50 \%$, there was no heterogeneity between the literature, and the fixed effects model was adopted.

\section{Results}

\section{Retrieval results and literature quality evaluation}

According to the relevant subject words, 189 publications related to PHN risk factors were retrieved through PubMed. According to the literature screening criteria, 14 studies were further selected for meta-analysis. Logistic regression analysis was used to screen the independent risk factors of PHN. A total of 4,192 patients with herpes zoster were included in the 14 studies, including 478 (11.40\%) patients with neuralgia and 3,714 (88.60\%) patients without neuralgia. Among the 14 studies, 3 were high quality, 11 were medium quality, and 0 were low quality. The document screening flowchart is shown in Figure 1.

\section{Age is an independent risk factor of PHN}

Eleven of the 14 studies used age as an independent variable to explore its relationship with PHN. In this study, age was combined and calculated. Taking age $<60$ as the reference, there was heterogeneity among the 11 studies $\left(\chi^{2}=26.37\right.$; $\left.\mathrm{P}=0.003 ; \mathrm{I}^{2}=62 \%\right)$. The results of the meta-analysis using the random effects model showed that age was an independent risk factor for PHN [OR $=1.59 ; 95 \%$ CI: $(1.23$, 2.04)], which was statistically significant $(Z=3.62 ; P<0.001)$, as shown in Figure 2. The funnel plot shows that each point is distributed on both sides within the CI in an inverted funnel shape, indicating no obvious publication bias or geographic bias, as shown in Figure 3. 


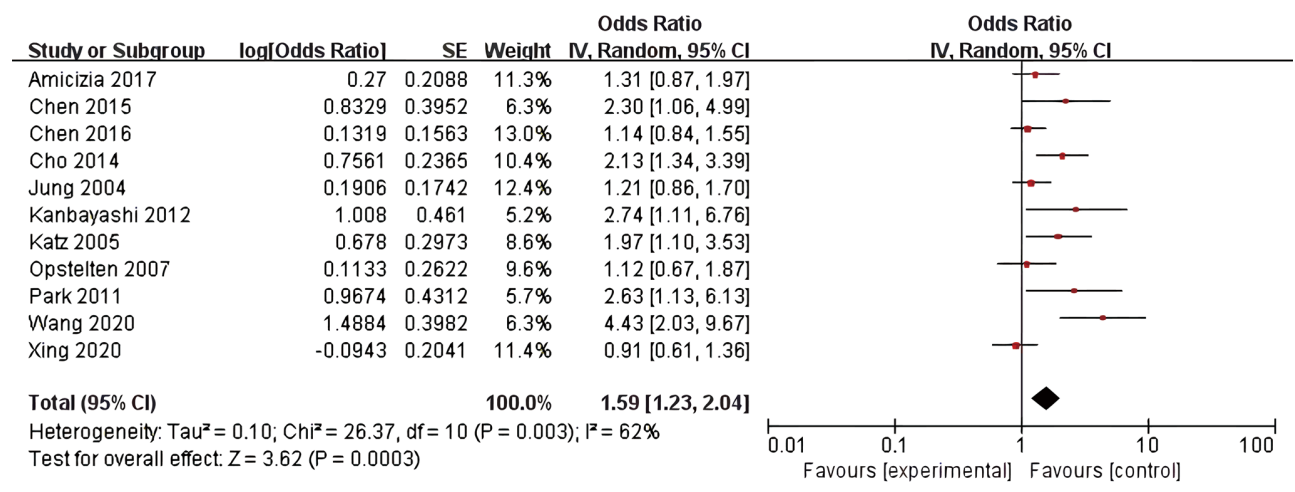

Figure 2 Meta-analysis of age as a risk factor of PHN. PHN, postherpetic neuralgia.

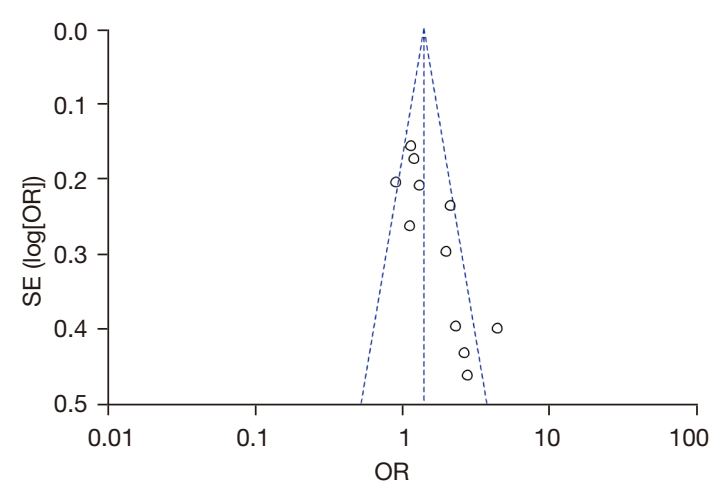

Figure 3 Funnel plots of the meta-analysis of age as a risk factor for PHN. PHN, postherpetic neuralgia.

\section{Acute severe pain is an independent risk factor of PHN}

Among the 14 studies, 12 took acute severe pain in the herpetic period as an independent variable to explore its relationship with PHN. There was heterogeneity among the 12 studies $\left(\chi^{2}=38.19 ; \mathrm{P}<0.001 ; \mathrm{I}^{2}=71 \%\right)$. Meta-analysis using the random effects model showed that acute severe pain in the herpetic stage was an independent risk factor for PHN [OR $=1.49 ; 95 \%$ CI: $(1.08,2.08)]$, which was statistically significant $(\mathrm{Z}=2.39 ; \mathrm{P}=0.02)$, as shown in Figure 4. The funnel plot shows that each point is distributed on both sides within the CI in an inverted funnel shape, indicating no obvious publication bias or geographic bias, as shown in Figure 5.

\section{Sex is an independent risk factor of $\mathrm{PHN}$}

Six of the 14 studies used gender as an independent variable and men as a reference to explore the relationship between gender and PHN. There was no significant heterogeneity among the 6 studies $\left(\chi^{2}=7.51 ; \mathrm{P}=0.19 ; \mathrm{I}^{2}=33 \%\right)$. The fixed effects model was used for meta-analysis. The results showed that gender was not statistically significant as a risk factor for $\mathrm{PHN}(\mathrm{Z}=0.37 ; \mathrm{P}=0.71)$, as shown in Figure 6. The funnel plot shows that the points are distributed on both sides within the CI in an inverted funnel shape, indicating no obvious publication bias or geographic bias, as shown in Figure 7.

\section{Severe rash is an independent risk factor of $\mathrm{PHN}$}

Nine of the 14 studies used severe herpes as an independent variable to explore its relationship with PHN. The heterogeneity among the 9 studies was not significant $\left(\chi^{2}=4.40 ; \mathrm{P}=0.82 ; \mathrm{I}^{2}=0 \%\right)$, and the random effects model was used for meta-analysis. The results showed that severe rash was an independent risk factor for PHN [OR $=2.40$; $95 \%$ CI: $(1.83,3.14)]$, which was statistically significant $(\mathrm{Z}=6.38$; $\mathrm{P}<0.001)$, as shown in Figure 8. The funnel plot shows that the points are distributed on both sides within the CI in an inverted funnel shape, indicating no obvious publication bias or geographic bias, as shown in Figure 9.

\section{Prodromal symptoms are an independent risk factor of PHN}

Four of the 14 studies used prodromal symptoms as independent variables to explore the relationship between prodromal symptoms and PHN. The heterogeneity among the 4 studies was not significant $\left(\chi^{2}=1.32 ; \mathrm{P}=0.72\right.$; $\left.\mathrm{I}^{2}=0 \%\right)$. The fixed effects model was used for meta-analysis. The results showed that prodromal symptoms were an independent risk factor for $\mathrm{PHN}[\mathrm{OR}=2.00 ; 95 \% \mathrm{CI}$ : $(1.16,3.44)]$, which was statistically significant $(Z=2.48$; 


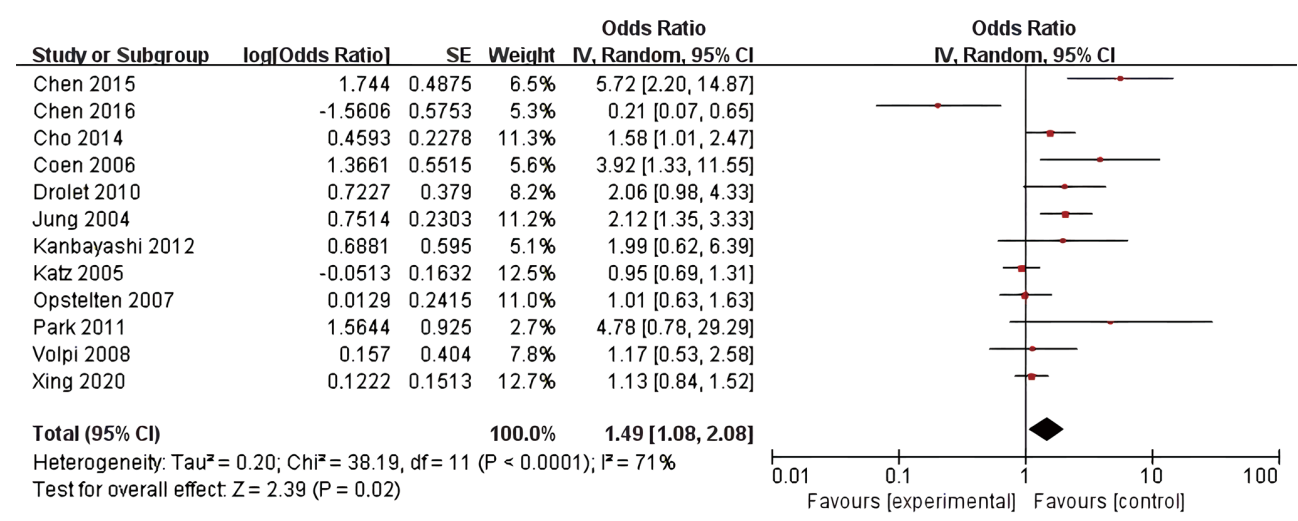

Figure 4 Meta-analysis of acute severe pain in the herpes zoster stage as a risk factor of PHN. PHN, postherpetic neuralgia.

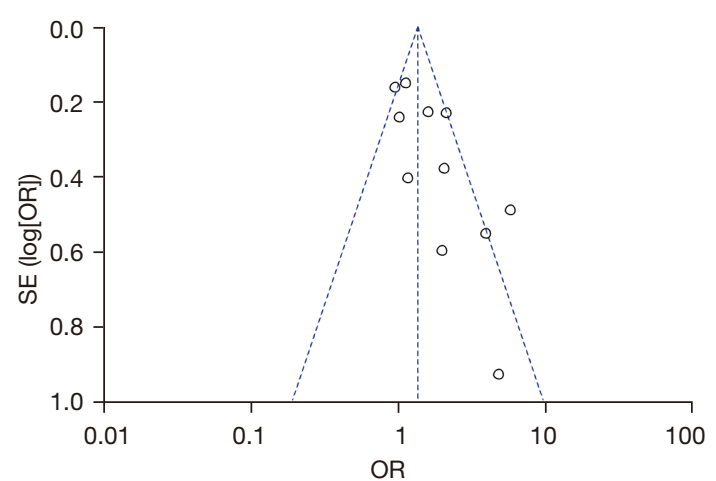

Figure 5 Funnel plots of the meta-analysis of acute severe pain in the herpes zoster stage as a risk factor for PHN. PHN, postherpetic neuralgia.

$\mathrm{P}=0.01$ ), as shown in Figure 10. The funnel plot shows that the points are distributed on both sides within the $\mathrm{CI}$ in an inverted funnel shape, indicating no obvious publication bias or geographic bias, as shown in Figure 11.

\section{Discussion}

Acute herpes zoster virus infection can cause irreversible damage to the body's nervous system, including the central and peripheral nerves (19). This view has been recognized and confirmed by many studies, but how nerve damage occurs is not clear $(20,21)$. Moreover, current studies have not yet determined the mechanism of acute pain and persistent pain caused by herpes zoster virus infection (22). It should be emphasized that $\mathrm{PHN}$ is not the continuation of pain caused by acute herpes zoster over time but is related to sensory nerve demyelination and scar formation (20).
Some studies have pointed out that herpesvirus-induced persistent pain results from both peripheral nerve injury and continuous action of the virus. First, virus infection leads to nerve function injury, increased neuronal excitability, and increased sensitivity to pain. Second, the virus persists for a long time, and the body cannot remove it efficiently and quickly (23-25). However, some studies have pointed out that the incidence of signal processing in the central nervous system changes after herpes zoster virus infection. The occurrence of PHN is related to the coordination of the central nervous system. At present, there is a lack of effective treatment for PHN. The main treatment goal is to reduce pain, but research shows that the current treatment methods are ineffective for more than half of patients. It is of great clinical significance to explore the independent risk factors of PHN and carry out early clinical intervention.

This study included 4,192 patients with herpes zoster, including 478 patients with neuralgia and 3,714 patients without neuralgia. The incidence rate of $\mathrm{PHN}$ was about $11.40 \%$, slightly lower than that reported in the literature $(12.50 \%)$. We believe that the incidence rate of PHN in the epidemiological survey may be lower than the actual incidence rate, mainly due to the diagnosis. Some patients with mild PHN may choose to take over-the-counter drugs to reduce pain symptoms. A small number of patients with immunosuppressive diseases, such as systemic lupus erythematosus, leukemia, and AIDS, among others, in the treatment of primary diseases or special care were symptomatic treatment while ignoring the diagnosis of PHN.

In this study, the risk factors of PHN were systematically evaluated by meta-analysis. The results showed that age, acute severe pain in the herpes zoster stage, prodromal symptoms, and severe rash were independent risk factors of 


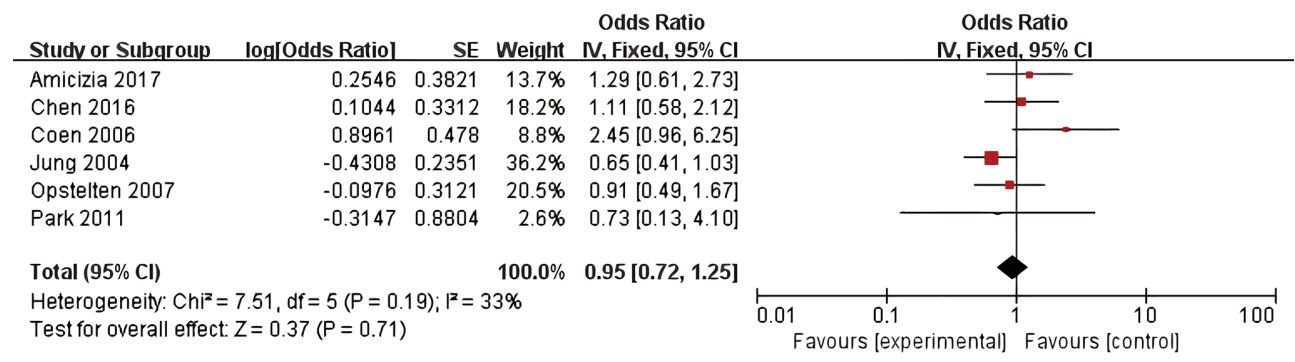

Figure 6 Meta-analysis of gender as a risk factor of PHN. PHN, postherpetic neuralgia.

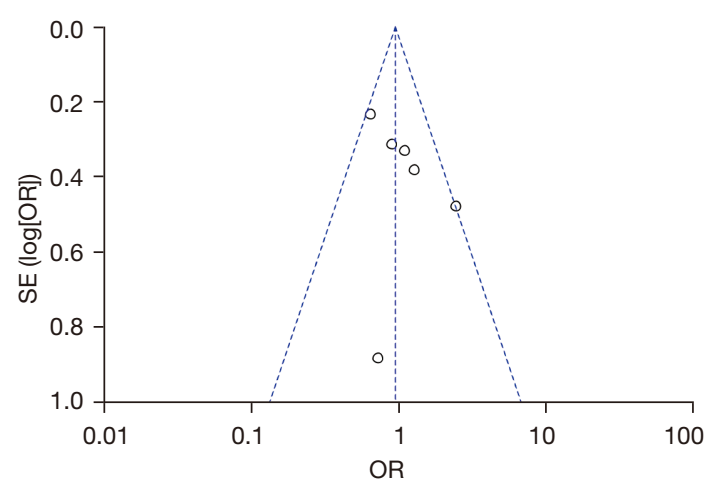

Figure 7 Funnel plots of the meta-analysis of gender as a risk factor for PHN. PHN, postherpetic neuralgia.

PHN. Most studies have confirmed age as an independent risk factor for PHN $(23,25)$. The possible reason is that cellular immune function decreases with age. When herpes zoster occurs, the body cannot effectively remove varicellazoster virus in the body, the virus level is in a high state for a long time, the nerve is seriously damaged by virus damage, and the nerve repair function of elderly patients is weakened, which finally increases the risk of PHN. Studies have shown that the incidence rate of PHN in herpes zoster patients over 50 is about $50 \%$, which is far higher than the incidence rate of $9 \%$ to $13 \%$ in other age groups. The meta-analysis results showed that acute severe pain in the herpes zoster stage was one of the independent risk factors of PHN. This result is consistent with some previous research results. Some studies have pointed out that the degree of pain in the acute phase is positively correlated with the severity of nerve injury. The more severe the pain in the herpes phase, the more severe the degree of nerve injury, and the risk of PHN increases accordingly. The local change of the rash site is one of the inducing factors of nerve injury. Its severity may be related to the degree of nerve injury. Severe rashes may promote reactivation of herpes zoster and more significant nerve damage, resulting in an increased risk of PHN (26). For the above reasons, some studies have also taken severe rash as one of the variables and confirmed that it is an independent risk factor for PHN $(23,27)$. The results of the meta-analysis showed that severe rash was an independent risk factor for PHN. Prodromal symptoms are also an independent risk factor for PHN, which increases the risk of PHN. Conversely, prodromal symptoms indicate the early replication of the herpes zoster virus in the affected ganglion, resulting in more significant nerve damage. On the other hand, when prodromal pain but no skin lesions occur, the patient may delay the treatment time because of an unknown diagnosis.

In addition to these risk factors, this study also found that gender cannot be determined as an independent risk factor for PHN. This is consistent with the results of some other comprehensive studies and individual studies. The results of all the literatures included in our analysis indicate that gender is not a risk factor for PHN. There are some limitations of this study. The possible risk factors or protective factors of $\mathrm{PHN}$ include immunosuppressive status, early glucocorticoid therapy, vaccine use, and antiviral therapy, among others. However, due to the small amount of data in the literature and confounding factors, this study did not conduct a systematic evaluation. The literature included in this paper were retrospective analyses, and there might be recall bias in the follow-up process. In addition, there is a lack of a unified and precise definition of PHN. Some studies evaluated all degrees of pain, and some studies only retained cases of severe pain. PHN with different pain levels was not stratified in this paper.

In conclusion, the meta-analysis results showed that age, acute severe pain during herpes zoster, prodromal symptoms, and severe rash were independent risk factors for PHN. 


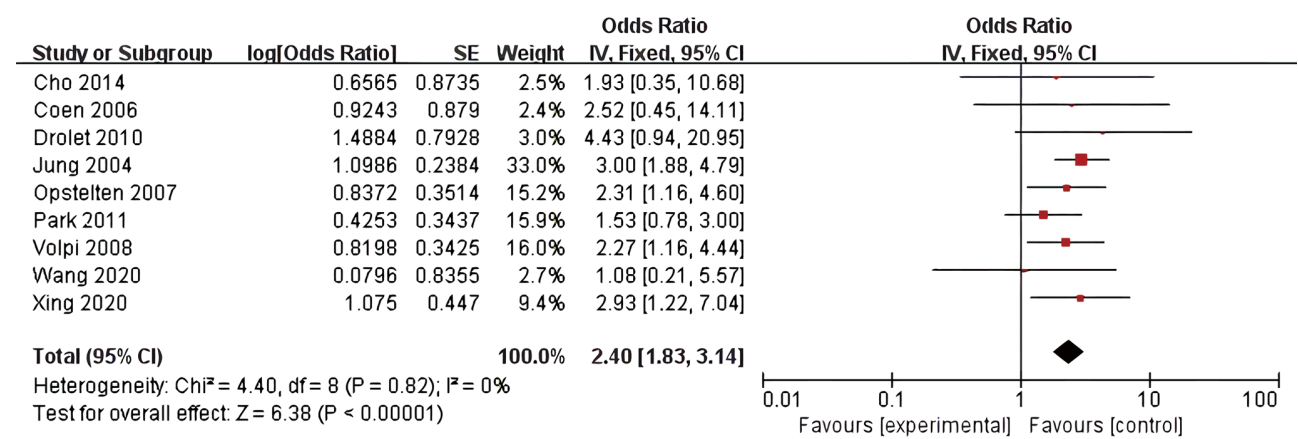

Figure 8 Meta-analysis of severe rash as a risk factor of PHN. PHN, postherpetic neuralgia.

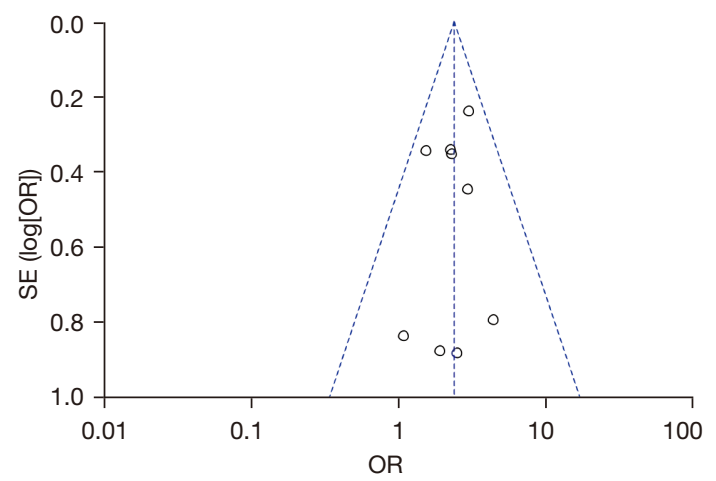

Figure 9 Funnel plots of the meta-analysis of severe rash as a risk factor for PHN. PHN, postherpetic neuralgia.

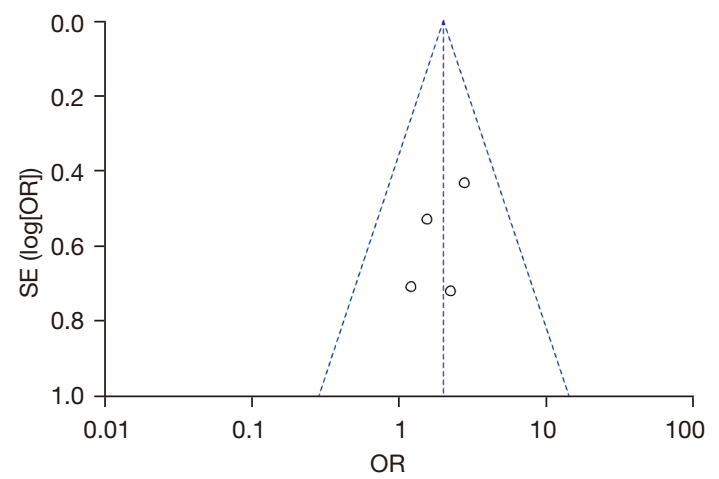

Figure 11 Funnel plots of the meta-analysis of prodromal symptoms as a risk factor for PHN. PHN, postherpetic neuralgia.

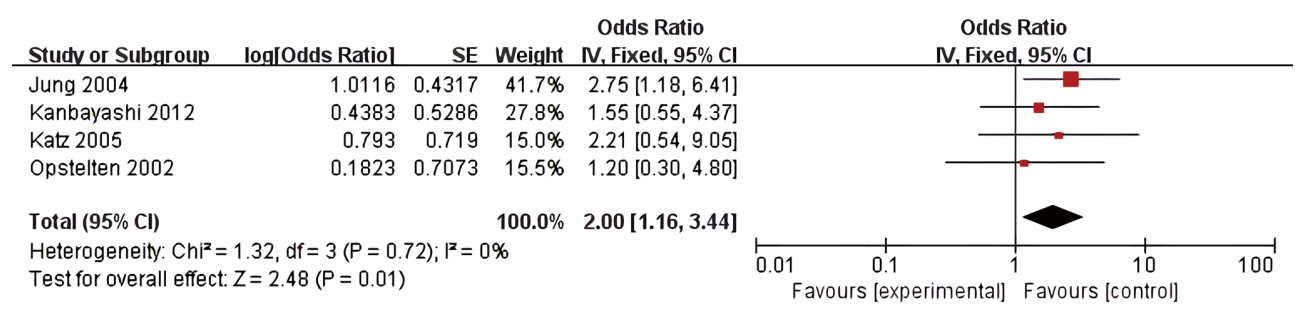

Figure 10 Meta-analysis of prodromal symptoms as a risk factor of PHN. PHN, postherpetic neuralgia.

\section{Acknowledgments}

Funding: The study was supported by Jiaxing Science and Technology Plan Project (2020AY30002) and Jiaxing Science and Technology Plan Project (2019AD32159).

\section{Footnote}

Reporting Checklist: The authors have completed the PRISMA reporting checklist. Available at https://dx.doi. org/10.21037/apm-21-3028

Conflicts of Interest: All authors have completed the ICMJE uniform disclosure form (available at https://dx.doi. org/10.21037/apm-21-3028). The authors have no conflicts of interest to declare.

Ethical Statement: The authors are accountable for all aspects of the work in ensuring that questions related to the accuracy or integrity of any part of the work are 
appropriately investigated and resolved.

Open Access Statement: This is an Open Access article distributed in accordance with the Creative Commons Attribution-NonCommercial-NoDerivs 4.0 International License (CC BY-NC-ND 4.0), which permits the noncommercial replication and distribution of the article with the strict proviso that no changes or edits are made and the original work is properly cited (including links to both the formal publication through the relevant DOI and the license). See: https://creativecommons.org/licenses/by-nc-nd/4.0/.

\section{References}

1. Wang XX, Zhang Y, Fan BF. Predicting postherpetic neuralgia in patients with herpes zoster by machine learning: a retrospective study. Pain Ther 2020;9:627-35.

2. Cohen E. Herpes zoster and postherpetic neuralgia. Clin Infect Dis 2020. [Epub ahead of print]. doi: 10.1093/cid/ ciaal192.

3. Schutzer-Weissmann J, Farquhar-Smith P. Post-herpetic neuralgia - a review of current management and future directions. Expert Opin Pharmacother 2017;18:1739-50.

4. Forbes HJ, Bhaskaran K, Thomas SL, et al. Quantification of risk factors for postherpetic neuralgia in herpes zoster patients: a cohort study. Neurology 2016;87:94-102 .

5. Amicizia D, Domnich A, Arata L, et al. The role of age-sex interaction in the development of post-herpetic neuralgia. Hum Vaccin Immunother 2017;13:376-8.

6. Johnson RW, Rice AS. Clinical practice. Postherpetic neuralgia. N Engl J Med 2014;371:1526-33.

7. Kanbayashi Y, Onishi K, Fukazawa K, et al. Predictive factors for postherpetic neuralgia using ordered logistic regression analysis. Clin J Pain 2012;28:712-4.

8. Drolet $M$, Brisson M, Schmader KE, et al. The impact of herpes zoster and postherpetic neuralgia on healthrelated quality of life: a prospective study. CMAJ 2010;182:1731-6.

9. Chen YT, Wang HH, Wang TJ, et al. Early application of low-level laser may reduce the incidence of postherpetic neuralgia (PHN). J Am Acad Dermatol 2016;75:572-7.

10. Coen PG, Scott F, Leedham-Green M, et al. Predicting and preventing post-herpetic neuralgia: are current risk factors useful in clinical practice? Eur J Pain 2006; 10:695-700.

11. Jung BF, Johnson RW, Griffin DR, et al. Risk factors for postherpetic neuralgia in patients with herpes zoster. Neurology 2004;62:1545-51.
12. Chen JY, Lan KM, Sheu MJ, et al. Peptic ulcer as a risk factor for postherpetic neuralgia in adult patients with herpes zoster. J Med Virol 2015;87:222-9.

13. Volpi A, Gatti A, Pica F, et al. Clinical and psychosocial correlates of post-herpetic neuralgia. J Med Virol 2008;80:1646-52.

14. Opstelten W, Zuithoff NPA, van Essen GA, et al. Predicting postherpetic neuralgia in elderly primary care patients with herpes zoster: prospective prognostic study. Pain 2007;132 Suppl 1:S52-9.

15. Cho SI, Lee CH, Park GH, et al. Use of S-LANSS, a tool for screening neuropathic pain, for predicting postherpetic neuralgia in patients after acute herpes zoster events: a single-center, 12-month, prospective cohort study. J Pain 2014;15:149-56.

16. Katz J, McDermott MP, Cooper EM, et al. Psychosocial risk factors for postherpetic neuralgia: a prospective study of patients with herpes zoster. J Pain 2005;6:782-90.

17. Xing X, Sun K, Yan M. Delayed initiation of supplemental pain management is associated with postherpetic neuralgia: a retrospective study. Pain Physician 2020;23:65-72.

18. Park J, Jang WS, Park KY, et al. Thermography as a predictor of postherpetic neuralgia in acute herpes zoster patients: a preliminary study. Skin Res Technol 2012;18:88-93.

19. Schmader K. Herpes zoster. Ann Intern Med 2018;169:ITC19-31.

20. Hadley GR, Gayle JA, Ripoll J, et al. Post-herpetic neuralgia: a review. Curr Pain Headache Rep 2016;20:17.

21. Qiu Y, Hao ML, Cheng XT, et al. Bioinformatics analysis of genes and mechanisms in postherpetic neuralgia. Pain Res Manag 2020;2020:1380504.

22. Schug SA, Parsons B, Almas M, et al. Effect of concomitant pain medications on response to pregabalin in patients with postherpetic neuralgia or spinal cord injuryrelated neuropathic pain. Pain Physician 2017;20:E53-63.

23. Forbes HJ, Thomas SL, Smeeth L, et al. A systematic review and meta-analysis of risk factors for postherpetic neuralgia. Pain 2016;157:30-54.

24. Jones J. Postherpetic neuralgia. J Pain Palliat Care Pharmacother 2015;29:180-1.

25. Sato K, Adachi K, Nakamura H, et al. Burden of herpes zoster and postherpetic neuralgia in Japanese adults 60 years of age or older: results from an observational, prospective, physician practice-based cohort study. J Dermatol 2017;44:414-22.

26. Mallick-Searle T, Snodgrass B, Brant JM. Postherpetic neuralgia: epidemiology, pathophysiology, and pain 
management pharmacology. J Multidiscip Healthc 2016;9:447-54.

27. Nagasako EM, Johnson RW, Griffin DR, et al. Rash severity in herpes zoster: correlates and relationship to postherpetic neuralgia. J Am Acad Dermatol 2002;46:834-9.

(English Language Editor: C. Betlzar)

Cite this article as: Zhou $\mathrm{H}$, Wang Z, Jin H, Chen X, Lei L. A systematic review and meta-analysis of independent risk factors for postherpetic neuralgia. Ann Palliat Med 2021;10(12):12181-12189. doi: 10.21037/apm-21-3028 